\title{
Qualidade fisiológica de sementes de cenoura classificadas por tamanho
}

\author{
Physiological quality of carrot seeds classified by size
}

\author{
Valdecir José dos Santos ${ }^{\mathrm{I}}$ Danton Camacho Garcia ${ }^{\mathrm{II}}$ Sidinei José Lopes ${ }^{\mathrm{II}}$ \\ Luiz Eichelberger ${ }^{\text {III }}$
}

RESUMO

\begin{abstract}
A obtenção de sementes de cenoura (Daucus carota L.) com alta qualidade está restrita à elevada heterogeneidade na maturação fisiológica, pois produz sementes em épocas diferentes e de tamanhos variados. A classificação de sementes de cenoura por tamanho pode ser uma boa alternativa para a melhoria da qualidade fisiológica. Para discriminar lotes de sementes por qualidade fisiológica, bem como identificar testes que forneçam uma estimativa do desempenho de sementes classificadas por tamanho, desenvolveu-se um experimento com três lotes de sementes de cenoura das cultivares 'Brasília' e 'Alvorada', sendo obtidos seis tratamentos distintos, dados pela combinação das duas cultivares com os lotes de tamanhos: médio, grande e extragrande. Nas cultivares 'Alvorada' e 'Brasília', apesar de não haver influência do tamanho das sementes na percentagem de germinação e no comprimento de parte aérea e total de plântulas, houve diferença significativa, além da massa seca de plântulas e do peso das sementes, para o comprimento de raiz, mostrando que essa variável foi a mais sensivel para diferenciar lotes pelo vigor. Assim, os lotes de sementes menores mostraram inferioridade na qualidade fisiológica em relação às sementes maiores, justificando a classificação de sementes por tamanho.
\end{abstract}

Palavras-chave: padronização de lotes de sementes, Daucus carota L, heterogeneidade na maturação fisiológica.

\section{ABSTRACT}

The acquisition of carrot (Daucus carota L.) seeds with high quality is restricted to the high heterogeneity at physiological maturity, because it produces seeds at different times and sizes. The classification of carrot seed by size can be a good alternative for improving the physiological quality. To differentiate seed lots by physiological quality, and identify tests that provide an estimate the performance of seed classified by size, it was developed an experiment with three seed lots of carrot cultivars 'Alvorada' and 'Brasília'. It was obtained six different treatments, given by combination of the two cultivars, which had medium, large and extra large size. At the cultivars 'Alvorada' and 'Brasilia', although there is no influence of seed size on germination percentage, shoot length and total seedling, there was a significant difference, in dry weight seedlings, seed weight, and root length. This shows that this variable was most sensitive to differentiate the existing lots. So, lots with small seeds showed inferiority in physiological quality in relation to larger seeds, justifying the classification of seeds by size.

Key words: size of seed, Daucus carota L, heterogeneity in physiological maturity.

\section{INTRODUÇÃO}

A cenoura (Daucus carota) destaca-se pelo valor nutritivo, sendo uma das principais fontes vegetais de pró-vitamina A (SPINOLA et al., 1998). A taxa de uso de sementes certificadas de hortaliças no Brasil é elevada; no entanto, a produção nacional de sementes é pequena. As importações de sementes de hortaliças perfazem um gasto anual de

'Centro de Educação Superior Norte (CESNORS), Universidade Federal de Santa Maria (UFSM), 98400-000, Frederico Westphalen, RS, Brasil. E-mail: agrvaldecir@gmail.com. Autor para correspondência.

"Departamento de Fitotecnia, Centro de Ciências Rurais (CCR), UFSM, Santa Maria, RS, Brasil.

IIISetor de Multiplicação de Sementes Genéticas, Embrapa Trigo, Passo Fundo, RS, Brasil. 
aproximadamente 34 milhões de reais, em que dois milhões de reais são destinados a sementes de cenoura. É uma das hortaliças mais cultivadas no Brasil, sendo a de maior expressão econômica entre as que têm como parte comestível a raiz (FILGUEIRA, 2003), e o Rio Grande do Sul é o maior produtor de sementes dessa espécie.

Sob condições de baixas temperaturas do ar ou em dias longos, a cenoura passa da fase vegetativa para a reprodutiva, emitindo um pendão floral que termina numa inflorescência tipo umbela composta, e esse pendão emite ramificações secundárias, terciárias, etc. (FERREIRA et al., 1991). Devido a este tipo de inflorescência, a cenoura não possui maturação fisiológica uniforme, diferenciando as sementes em tamanho e qualidade (NASCIMENTO, 1991). As sementes de cenoura são colhidas por etapas, e as oriundas da umbela primária tendem a serem maiores e sucessivamente menores para as umbelas secundárias, terciárias, etc. (RODO et al., 2001).

Há uma tendência de as sementes grandes apresentarem melhor desempenho fisiológico que as sementes menores da mesma espécie e cultivar, proporcionando um desenvolvimento mais rápido às mudas (POPINIGIS, 1985; CARVALHO \& NAKAGAWA, 2000). Essa diversidade de comportamento das sementes de diferentes tamanhos torna necessária uma padronização capaz de definir quais sementes são capazes de expressar satisfatoriamente as qualidades físicas e fisiológicas da espécie. Isso demanda ações de pesquisa que propiciem informações suficientes para uma adequada orientação das instituições produtoras de sementes.

O tamanho das sementes pode influenciar a qualidade destas, pois as de maior tamanho, por possuírem maior material de reserva, apresentam maior potencial fisiológico, ao contrário das menores, que apresentam tendência à baixa germinação e vigor de plântulas. Para CARVALHO \& NAKAGAWA (2000), em geral, as sementes maiores receberam maior quantidade de nutrientes durante o seu desenvolvimento, possuindo maior quantidade de substâncias de reservas e embriões bem formados, sendo mais vigorosas. Também HAIG \& WESTOBY (1991) relatam que a maior quantidade de reserva aumenta a probabilidade de sucesso no estabelecimento de plântulas, permitindo a sobrevivência por maior tempo em condições ambientais desfavoráveis. POPINIGIS (1985) afirma que o maior tamanho das sementes, em muitas espécies, é indicativo de melhor germinação e vigor.
Algumas características das sementes de cenoura, tais como: formato irregular, dormência e desuniformidade de germinação, fazem com que a emergência seja uma das fases mais críticas do ciclo dessas plantas. Assim, a qualidade fisiológica das sementes de cenoura produzidas e/ou comercializadas no Brasil nem sempre se enquadra dentro dos padrões mínimos de comercialização estabelecidos pelos órgãos reguladores do processo de produção de sementes (NASCIMENTO \& REIFSCHNEIDER, 1986), especialmente as sementes de cultivares do grupo Brasília, cuja qualidade fisiológica das sementes, principalmente em relação à germinação, é inferior à das cultivares importadas, atualmente utilizados no país.

A qualidade dos lotes de sementes a serem comercializados para fins de semeadura é avaliada por meio do teste de germinação, o qual é realizado sob condições ideais e artificiais que permitem a manifestação do máximo potencial de germinação (AOSA, 1983). Porém, no campo, as sementes poderão estar sujeitas a uma série de condições adversas, tais como: excesso ou déficit hídrico, obstrução mecânica imposta por compactação da camada de solo que as cobre e ataque de microorganismos e insetos (PERRY, 1981), fazendo com que a percentagem de emergência de plântulas seja geralmente menor que os resultados obtidos no teste de germinação.

O trabalho tem como objetivos avaliar o potencial fisiológico de sementes de cenoura classificadas por tamanho e selecionar métodos laboratoriais para discriminar lotes de sementes por diferenças no vigor.

\section{MATERIAL E MÉTODOS}

Os experimentos foram conduzidos no Laboratório Didático e de Pesquisa em Sementes (LDPS) do Departamento de Fitotecnia da Universidade Federal de Santa Maria (UFSM), Santa Maria, Rio Grande do Sul (RS), com sementes de cenoura de duas cultivares, 'Brasília' e 'Alvorada', produzidas pela empresa Isla Sementes Ltda, na safra 2007/2008. Para cada cultivar, foram utilizados três lotes comerciais, de tamanhos e densidades diferentes, classificados pela empresa e embaladas em latas de 100g. Assim, foram obtidos lotes de tamanho médio (M), grande (G) e extragrande (GG), das duas cultivares, totalizando seis tratamentos (Tabela 1). As sementes foram mantidas durante todo o período experimental nas embalagens de origem e mantidas em câmara fria a $10^{\circ} \mathrm{C}$ de temperatura do ar e umidade relativa de $30 \%$. 
Tabela 1 - Qualificação dos lotes de sementes médias (M), grandes (G) e extragrandes (GG) das cultivares 'Alvorada' e 'Brasília' quanto às variáveis comprimento de sementes (CS), largura de sementes (LS), área de sementes (AS) e peso de mil sementes (PMS). Santa Maria, 2009.

\begin{tabular}{|c|c|c|c|c|c|}
\hline \multirow{2}{*}{ Cultivar } & \multirow{2}{*}{ Lote } & CS & LS & \multirow{2}{*}{$\begin{array}{c}\mathrm{AS} \\
\mathrm{mm}^{2}\end{array}$} & \multirow{2}{*}{$\begin{array}{c}\text { PMS } \\
\text { g }\end{array}$} \\
\hline & & \multicolumn{2}{|c|}{---------- mm---------- } & & \\
\hline \multirow[t]{3}{*}{ 'Alvorada' } & $\mathrm{M}$ & $3,49 a^{*}$ & $1,69 \mathrm{a}$ & $4,50 \mathrm{a}$ & $1,41 \mathrm{a}$ \\
\hline & G & $2,94 \mathrm{~b}$ & $1,49 \mathrm{~b}$ & $3,39 \mathrm{~b}$ & $1,70 \mathrm{~b}$ \\
\hline & GG & $2,79 \mathrm{~b}$ & $1,30 \mathrm{c}$ & $2,84 \mathrm{c}$ & $2,33 \mathrm{c}$ \\
\hline \multirow[t]{3}{*}{ 'Brasília' } & M & $3,70 \mathrm{a}$ & $1,95 \mathrm{a}$ & $5,47 \mathrm{a}$ & $1,13 \mathrm{a}$ \\
\hline & G & $3,16 b$ & $1,60 \mathrm{~b}$ & $3,74 \mathrm{~b}$ & $1,49 \mathrm{~b}$ \\
\hline & GG & $2,92 \mathrm{c}$ & $1,50 \mathrm{c}$ & $3,02 \mathrm{c}$ & $2,09 \mathrm{c}$ \\
\hline
\end{tabular}

* Médias não seguidas pela mesma letra na coluna diferem significativamente pelo Teste de Tukey, com nível de 5\% de probabilidade de erro.

Para a determinação das variáveis relativas à qualificação dos lotes de sementes, utilizou-se a técnica de análise de imagens. Para isso, foram obtidas imagens digitais de quatro repetições de cinquenta sementes por lote, as quais foram descarregadas em um microcomputador e processadas pelo software de análise de imagem SigmaScan Pro V.5.0, da empresa Jandel Cientific, que é um software que possui ferramentas de interpolação de pontos, possibilitando a determinação de distâncias ou áreas.

Para a obtenção do peso de mil sementes (PMS em g), foram realizadas contagem e pesagem de 10 repetições de 100 sementes por lote, procedendo-se à média aritmética das repetições, sendo obtido o peso de 100 sementes. Esse resultado foi multiplicado por 10 para ser obtido o peso de mil sementes. Foi realizada a estimativa do grau de umidade (U) nas sementes utilizadas na determinação do PMS. Para a determinação do grau de umidade das sementes, foi utilizado o método da estufa, a $105^{\circ} \mathrm{C}$, por 24 horas, segundo as Regras de Análise de Sementes (BRASIL, 1992).

O teste de germinação $(\mathrm{G})$ foi realizado com quatro repetições de 50 sementes cada. As sementes foram acomodadas individualmente em substrato de papel germtest umedecido com água destilada na proporção de 2,5 vezes o peso do papel seco (MENEZES et al., 1993). As repetições foram colocadas em embalagens de plástico e mantidas em um germinador regulado à temperatura constante de $25^{\circ} \mathrm{C}$. A contagem das sementes germinadas foi realizada aos oito dias. Considerou-se, para a percentagem de germinação, o número de plântulas normais, ou seja, que apresentem estruturas essenciais, como: radícula, coleóptilo e cotilédones bem formados.
Em conjunto com o teste de germinação, foram conduzidas a primeira contagem de germinação (PC), contagem de plântulas anormais e sementes mortas, realizada aos oito dias após a semeadura (AOSA, 1983). Foram consideradas plântulas anormais as que apresentam qualquer uma das suas estruturas essenciais ausentes, deformadas, muito danificadas ou infectadas por patógenos da própria semente (KRZYZANOWSKI et al., 1991; BRASIL, 1992), e sementes mortas, as sementes que, ao final dos testes, não estavam duras nem dormentes, mas com uma coloração escura e intensa, parcial ou totalmente podres (MATA et al., 1985).

Com as plântulas normais do teste de germinação, efetuaram-se medidas de dimensões de plântulas, em que foram observados o comprimento de parte aérea (CPA), comprimento de raiz (CR) e comprimento total (CT) de plântulas, o qual foi obtido pela soma das duas variáveis anteriores. Foram utilizadas 10 plântulas normais por repetição do teste de germinação, obtidas aleatoriamente, sendo avaliadas por régua milimetrada e por imagens. Determinou-se ainda, com essas plântulas, a massa seca de plântulas (MSP), incluindo todas as partes das plântulas: radícula, hipocótilo, cotilédones e folhas primárias. Estas foram devidamente colocadas em embalagens de papel e levadas para secar em estufa, com temperatura de $70^{\circ} \mathrm{C}$, sendo essas embalagens pesadas com balança de precisão até ser alcançado peso constante.

Para determinação do índice de velocidade de germinação (IVG), seguiu-se a metodologia proposta por MAGUIRE (1962), sendo realizada a semeadura de quatro repetições de 100 sementes por lote em substrato de papel umedecido com água destilada, na proporção de duas vezes e meia o peso do papel, os substratos foram colocados em caixas plásticas do tipo gerbox, sendo realizadas contagens diárias das sementes germinadas.

A avaliação do envelhecimento acelerado (EA) de sementes serve de parâmetro para estimar o potencial de armazenagem dos lotes de sementes. Assim esse teste foi conduzido conforme a metodologia proposta pela AOSA (1983), sendo utilizadas 200 sementes por lote. As sementes foram distribuídas sobre bandejas de tela de alumínio, as quais foram fixadas no interior de caixas plásticas tipo gerbox. As caixas foram mantidas em uma estufa, com temperatura constante de $41^{\circ} \mathrm{C}$ e umidade relativa de $100 \%$, por um período de 48 horas. Após esse período, as sementes foram colocadas para germinar, seguindo as recomendações para o teste de germinação (BRASIL, 1992). A avaliação das plântulas foi realizada 
sete dias após a semeadura, computando-se a percentagem de plântulas normais.

Efetuou-se ainda a semeadura em bandejas multiceluladas de poliestireno expandido, contendo 200 células, as quais foram preenchidas com substrato comercial Plantmax ${ }^{\circledR}$. Em cada bandeja, foram utilizadas quatro repetições de 50 sementes, sendo quatro repetições por lote e casualizando-as por bandeja as sementes foram colocadas sobre o substrato e cobertas por uma espessura de três milímetros do mesmo substrato. Durante o período experimental, as bandejas foram mantidas em casa-devegetação. Assim, obteve-se o índice de velocidade da emergência das plântulas (IVE), anotando-se diariamente, no mesmo horário, o número de plântulas que apresentaram cotilédones visíveis. Ao final do teste, com os dados diários do número de plântulas normais, foi calculado o IVE empregando-se a fórmula proposta por MAGUIRE (1962) $I V E=\sum_{i=1}^{n} N_{i} / D_{i}$ (1), em que Ni é o número de plântulas emersas no dia, Di é o iésimo dia após a semeadura e n é o número total de dias do teste, sendo i o índice de variação.

O delineamento utilizado foi o inteiramente casualizado. Os dados obtidos em cada teste foram analisados separadamente por meio da análise de variância, utilizando-se o Sistema de Análise Estatística (SANEST). Os dados, em números decimais, relativos a contagens de plântulas ou sementes (Germinação, primeira contagem, plântulas anormais, sementes mortas, emergência, teste de frio e envelhecimento acelerado), foram submetidos à transformação arco seno da raiz de ' $\mathrm{x}$ '. As médias foram comparadas por contrastes ortogonais, nos quais foi decomposta a soma de quadrados de tratamentos em contrastes, com a finalidade de testar o efeito de tamanho das sementes e suas respostas a testes laboratoriais. Assim utilizouse a família de contrastes mostrada na tabela 2 .

\section{RESULTADOS E DISCUSSÃO}

Na comparação das médias por contrastes ortogonais mostrados na tabela 3, verifica-se que, no contraste C1, as cultivares 'Alvorada' (A) e 'Brasília' diferiram significativamente apenas no índice de velocidade de germinação (IVG). Essa diferença é explicada pelas características fenotípicas e fisiológicas de cada cultivar. Quando comparadas as sementes médias (M) com a combinação de sementes grandes (G) e extragrandes (GG) na cultivar 'Alvorada' (C2), notam-se diferenças estatísticas para quase todas as variáveis, exceto para germinação, primeira contagem, plântulas anormais e comprimento de parte aérea (CPA). Comportamento semelhante é observado para a cultivar 'Brasília' no terceiro contraste.

Diferenças significativas de comprimento de raiz e de parte aérea, assim como de massa seca de plântulas (Tabela 3), são indícios de diferenças na qualidade fisiológica das sementes, pois o vigor das sementes é o reflexo de um conjunto de características ou propriedades que determinam o seu potencial fisiológico, ou seja, a capacidade de apresentar desempenho adequado quando expostas a diferentes condições ambientais (MARCOS FILHO, 1994).

Nos contrastes C4 e C5, comparam-se as sementes grandes $(\mathrm{G})$ com as extragrandes (GG) para as cultivares 'Alvorada' e 'Brasília', respectivamente. São verificados novamente os benefícios da classificação, pois há diferenças no peso de mil sementes (Tabela 3). No entanto, verificase que há pouca diferença nas demais variáveis, o que mostra qualidade fisiológica semelhante entre esses dois tamanhos de sementes, sendo possível, sob o ponto de vista de qualidade fisiológica de semente, misturar esses lotes ou não estratificá-los no beneficiamento.

Observa-se, no primeiro contraste, que o índice de velocidade de germinação (IVG) foi maior na cultivar 'Alvorada', evidenciando a menor qualidade fisiológica da cultivar 'Brasília'. Já para o índice de velocidade de germinação (IVG), é possível verificar que, nos contrastes C2 e C3, as sementes maiores (combinação de sementes grandes e extragrandes) foram significativamente melhores que as sementes médias para ambas as cultivares, apontando melhor vigor para sementes de maior tamanho. Esses resultados discordam dos encontrados por RODO et al. (2001), porém essa diferença no vigor pode ser explicada pela maior

Tabela 2 - Coeficiente dos contrastes ortogonais para comparação de lotes de sementes de cenoura das cultivares 'Alvorada' (A) e 'Brasília' (B), com sementes médias (M), grandes (G), extragrandes (GG). Santa Maria, 2007.

\begin{tabular}{lccccc}
\hline Tratamentos & $\mathrm{C}_{1}$ & $\mathrm{C}_{2}$ & $\mathrm{C}_{3}$ & $\mathrm{C}_{4}$ & $\mathrm{C}_{5}$ \\
\hline $\mathrm{AM}$ & 1 & 2 & 0 & 0 & 0 \\
$\mathrm{AG}$ & 1 & -1 & 0 & 1 & 0 \\
$\mathrm{AGG}$ & 1 & -1 & 0 & -1 & 0 \\
$\mathrm{BM}$ & -1 & 0 & 2 & 0 & 0 \\
$\mathrm{BG}$ & -1 & 0 & -1 & 0 & -1 \\
$\mathrm{BGG}$ & -1 & 0 & -1 & 0 & 1 \\
$\sum_{i} C_{i}=$ & 0 & 0 & 0 & 0 & 0 \\
\hline
\end{tabular}


quantidade de reserva dessas sementes (CARVALHO \& NAKAGAWA, 2000), mostrada pela significância das diferenças no peso de mil sementes (PMS). Notase, ainda, nos contrastes $\mathrm{C} 4$ e C5 da tabela 3, que houve uma inversão nos resultados, mostrando inferioridade das sementes extragrandes em relação às grandes, tanto para IVG, como para IVE, porém esses resultados não são significativos para a cultivar 'Alvorada', mas pode ser explicado pelo fato de as sementes extragrandes serem oriundas de umbelas primárias, que ficam fisiologicamente maduras primeiro, no campo, e perdem parte de sua qualidade até que as demais umbelas amadureçam e permitam a colheita (RODO et al., 2001).

Os valores de germinação foram baixos e não apresentaram diferenças estatísticas entre lotes das duas cultivares (Tabela 3). A umidade dos lotes apresentou-se relativamente baixa, podendo ter causado uma absorção de água com mais intensidade, característica de sementes pequenas, causando a deterioração das sementes, o que é mostrado pelos altos valores de sementes mortas (RODO et al., 2000). As sementes de maior tamanho possuem maior dificuldade de perderem sua umidade durante a secagem e por isso são armazenadas com um maior teor de umidade, favorecendo uma taxa de respiração maior nessas sementes; além disso, as sementes maiores sofrem mais danos mecânicos no processo de desaristamento (NASCIMENTO \& ANDREOLI, 1990). Essas características podem ter influenciado negativamente o processo de germinação, explicando os valores encontrados.

Para a variável peso de mil sementes, foi observado comportamento coerente com a germinação, pois sementes mais pesadas apresentam mais material de reserva para o processo germinativo (NASCIMENTO \& ANDREOLI, 1990).

\section{CONCLUSÃO}

A análise de comparação de médias por contrastes ortogonais é capaz de discriminar lotes de sementes de cenoura pela qualidade fisiológica. Nas cultivares de cenoura 'Alvorada' e 'Brasília', o tamanho das sementes interfere positivamente no comprimento de raiz e massa seca de plântulas.

Tabela 3 - Contrastes ortogonais (C1, C2, C3, C4 e C5): germinação (G), primeira contagem (PC), plântulas anormais (An), sementes mortas (M), umidade (U), envelhecimento acelerado (EA), comprimento de parte aérea (CPA), de raiz (CR), total (CT) de plântulas, massa seca de plântulas (MSP), peso de mil sementes (PMS), índice de velocidade de germinação (IVG) e índice de velocidade de emergência (IVE) das cultivares 'Alvorada' (A) e 'Brasília' (B), com três tamanhos de sementes: médio (M), grande (G) e extragrande (GG). Santa Maria, RS, 2008.

\begin{tabular}{|c|c|c|c|c|c|c|c|c|c|c|c|c|c|c|}
\hline & & G & $\mathrm{PC}$ & An & M & $\mathrm{U}$ & EA & $\mathrm{CPA}$ & $\mathrm{CR}$ & CT & \multirow{2}{*}{$\begin{array}{l}\text { MSP } \\
\text { mg }\end{array}$} & \multirow{2}{*}{$\begin{array}{c}\text { PMS } \\
\text { g }\end{array}$} & \multirow{2}{*}{ IVG } & \multirow{2}{*}{ IVE } \\
\hline & & \multicolumn{6}{|c|}{ - } & \multicolumn{3}{|c|}{------------ mm ------------ } & & & & \\
\hline \multirow{2}{*}{$\mathrm{C} 1$} & A & 66 & 59 & 4 & 30 & 7,45 & 72 & 24,63 & 28,44 & 53,07 & 0,765 & 1,813 & 12,61 & 7,17 \\
\hline & B & 72 & 57 & 3 & 25 & 7,54 & 73 & 21,75 & 24,99 & 46,74 & 0,683 & 1,566 & 10,34 & 6,88 \\
\hline \multicolumn{2}{|c|}{ Signif. } & 0,116 & 0,678 & 0,487 & 0,162 & 0,742 & 0,900 & 0,080 & 0,134 & 0,088 & 0,407 & 0,153 & $0,000^{*}$ & 0,569 \\
\hline \multirow[b]{2}{*}{$\mathrm{C} 2$} & $\mathrm{AM}$ & 71 & 67 & 6 & 24 & 6,36 & 65 & 21,50 & 21,71 & 43,21 & 0,618 & 1,411 & 11,7 & 6,61 \\
\hline & $\begin{array}{l}\text { AG e } \\
\text { AGG }\end{array}$ & 64 & 56 & 3 & 33 & 7,99 & 76 & 26,19 & 31,80 & 57,99 & 0,838 & 2,014 & 13,06 & 7,45 \\
\hline \multicolumn{2}{|c|}{ Signif. } & 0,216 & 0,122 & 0,271 & $0,049 *$ & $0,000^{*}$ & 0,057 & 0,090 & $0,006^{*}$ & $0,014^{*}$ & $0,096^{*}$ & $0,006^{*}$ & $0,018^{*}$ & 0,145 \\
\hline \multirow[b]{2}{*}{$\mathrm{C} 3$} & $\mathrm{BM}$ & 69 & 50 & 2 & 30 & 7,52 & 75 & 18,60 & 23,50 & 42,10 & 0,428 & 1,125 & 9,24 & 7,49 \\
\hline & $\begin{array}{l}\text { BG e } \\
\text { BGG }\end{array}$ & 74 & 61 & 4 & 23 & 7,55 & 72 & 23,33 & 25,73 & 49,07 & 0,811 & 1,787 & 10,88 & 6,57 \\
\hline \multicolumn{2}{|c|}{ Signif. } & 0,362 & 0,089 & 0,237 & 0,229 & $0,001 *$ & 0,674 & $0,003^{*}$ & 0,345 & 0,058 & $0,006^{*}$ & $0,003^{*}$ & $0,014^{*}$ & 0,338 \\
\hline \multirow{2}{*}{$\mathrm{C} 4$} & $\mathrm{AG}$ & 68 & 65 & 0 & 32 & 7,48 & 79 & 28,20 & 33,40 & 61,60 & 0,69 & 1,725 & 13,36 & 8,07 \\
\hline & AGG & 62 & 50 & 5 & 33 & 8,30 & 72 & 24,99 & 30,84 & 55,83 & 0,927 & 2,187 & 12,76 & 6,84 \\
\hline \multicolumn{2}{|c|}{ Signif. } & 0,344 & 0,095 & 0,085 & 0,802 & $0,023^{*}$ & 0,325 & 0,382 & 0,555 & 0,436 & 0,172 & $0,048^{*}$ & 0,31 & 0,081 \\
\hline \multirow{2}{*}{$\mathrm{C} 5$} & BG & 79 & 65 & 4 & 18 & 7,55 & 85 & 23,30 & 24,46 & 47,76 & 0,648 & 1,485 & 11,75 & 8,07 \\
\hline & BGG & 69 & 58 & 4 & 28 & 7,54 & 59 & 23,37 & 27,00 & 50,37 & 0,975 & 2,089 & 10,02 & 5,08 \\
\hline \multicolumn{2}{|c|}{ Signif. } & 0,103 & 0,165 & 0,999 & 0,111 & 0,267 & $0,005^{*}$ & 0,964 & 0,412 & 0,561 & $0,006^{*}$ & $0,000^{*}$ & $0,001^{*}$ & $0,001 *$ \\
\hline
\end{tabular}

${ }^{*}$ Contraste significativo pelo teste de $\mathrm{F}$, em $5 \%$ de probabilidade de erro. 


\section{REFERÊNCIAS}

AOSA - Association of Official Seed Analysts (East Lasing, Estados Unidos). Seed vigor testing handbook. East Lasing, 1983. 93p. (Contribution, 32).

BRASIL, Ministério da Agricultura e Reforma Agrária. Regras para análise de sementes. Brasília: SNDA/DNDV/CLAV, 1992. 365p.

CARVALHO, N.M.; NAKAGAWA, J. Sementes: ciência tecnologia e produção. 4.ed. Jaboticabal: FUNEP, 2000. $588 \mathrm{p}$.

FERREIRA, M.D. et al. Cultura da cenoura. Guaxupe: Cooxupé, 1991. 20p.

FILGUEIRA, F.A.R. Novo manual de olericultura: agrotecnologia moderna na produção e comercialização de hortaliças. 2.ed. Viçosa: UFV, 2003. 412p.

HAIG, D.; WESTOBY, M. Seed size, pollination casts and angiosperm success. Evolutionary Ecology, London, v.5, p.231-247, 1991.

KRZYZANOWSKI, F.C. et al. Relato dos testes de vigor disponíveis para as grandes culturas. Informativo ABRATES, Londrina, v.1, n.2, p.42-47, 1991.

MAGUIRE, J.D. Speed of germination-aid in selection and evaluation for seedlig emergence and vigor. Crop Science, Madison, v.2, n.1, p.176-177, 1962.

MARCOS FILHO, J. Teste de envelhecimento acelerado. In: VIEIRA, R.D.; CARVALHO, N.M. (Eds.). Teste de vigor em sementes. Jaboticabal: FUNEP, 1994. 164p, p133-149.

MATA, M.E.R.M.C. et al. Deterioração de sementes armazenadas de algodão (Gossypium hirsutum L. r. latifolium H.). Revista Nordestina de Armazenagem, Campina Grande, v.2, n.1, p.37-56, 1985.
MENEZES, N.L. et al. Efeito do nível de umedecimento do substrato sobre a germinação de Curcubitaceae. Ciência Rural, Santa Maria, v.1, n.1, p.157-160, 1993.

NASCIMENTO, W.M. Efeito da ordem das umbelas na produção e qualidade de sementes de cenoura. Revista Brasileira de Sementes, Pelotas, v.13, n.2, p.131-133, 1991.

NASCIMENTO, W.M.; ANDREOLI, C. Controle de qualidade no beneficiamento de sementes de cenoura. Revista Brasileira de Sementes, Pelotas, v.12, n. 2, p.28-36, 1990.

NASCIMENTO, W.M.; REIFSCHNEIDER, F.J.B. Avaliação da qualidade sementes de cenoura cv. Brasília produzidas na região do Distrito Federal. Horticultura Brasileira, Brasília, v.4, n.2, p.36-42, 1986.

PERRY, D.A. Introduction: methodology and application of vigour tests; seedling growth and evaluation tests. In: PERRY, D.A. (Eds.). Handbook of vigour tests methods. Zürich: Int Seed Test Assoc, 1981. p.3-20.

POPINIGIS, F. Fisiologia da semente. 2.ed. Brasília: Ministério da Agricultura, Agiplan, 1985. 289p.

RODO, A.B. et al. Qualidade fisiológica e tamanho de sementes de cenoura. Scientia Agricola, Piracicaba, v.58, n.1, p.201204, 2001. Disponível em: <http://www.scielo.br/ scielo.php ? script=sci arttext\&pid=S 0103 $90162001000100031 \& \operatorname{lng}=$ pt\&nrm=iso $>$. Acesso em: 10 jul. 2010. doi: 10.1590/S0103-90162001000100031.

RODO, A.B. et al. Metodologia alternativa do teste de envelhecimento acelerado para sementes de cenoura. Scientia Agricola, Piracicaba, v.57, n.2, p.289-292, 2000. Disponível em: $<$ http://www.scielo.br/scielo.php?script=sci_arttext\&pid=S0103$90162000000200015 \& \operatorname{lng}=e n \& n r m=i s o>$. Acesso em 15 nov. 2009. doi: $10.1590 / \mathrm{S} 0103-90162000000200015$.

SPINOLA, M.C.M. et al. Comparação entre métodos para avaliação do vigor de sementes de cenoura. Revista Brasileira de Sementes, Pelotas, v.20, n.2, p.63-67, 1998. 